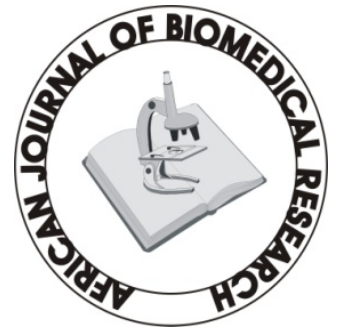

Full-text available at http://www.ajbrui.com http://www.bioline.br/md http://www.ajol.com

Received:

September 2007

Accepted (Revised):

February 2008

Published

May 2008
Full Length Research Article

\section{Body Mass Index at onset of Puberty in Rats Exposed to Aqueous Extract of Hibiscus Sabdariffa in Utero}

\author{
${ }^{* 1}$ Iyare, E. E. and ${ }^{2}$ Adegoke, O. A. \\ ${ }^{1}$ Dept of Physiology, College of Medicine, \\ University of Nigeria, Enugu campus, Enugu State. \\ ${ }^{2}$ Dept of Physiology, College of Medicine, \\ University of Lagos, Idiaraba, Lagos State.
}

\section{ABSTRACT}

The present study was designed to investigate whether or not maternal consumption of aqueous extract of Hibiscus sabdariffa (HS) during pregnancy has any effect on body weight, body mass index (BMI) and weights of some selected visceral organs at onset of puberty in the female offspring. Eighteen in-bred virgin female Sprague-Dawley rats aged between 10-12 weeks and weighing $125 \pm 5.5 \mathrm{~g}$ (mean \pm SEM) with two consecutive regular 4-day estrus cycle were randomly assigned to one of three groups of 6rats/group. One group had tap water (control); another had $1.5 \mathrm{~g}$-extract $/ \mathrm{kg}$ while the third group had 3.0g-extract/kg in their drinking water throughout pregnancy. Maternal fluid and food intake were recorded throughout pregnancy and offspring weights were recorded at birth, weaning and weekly thereafter until onset of puberty. Results showed that HS consumption during pregnancy significantly decreased maternal fluid and food intake; increased body weight, BMI and the weights of the kidney, liver, heart and spleen; and delays the onset of puberty in the female offspring.

(Afr. J. Biomed. Res. 11: 203 - 208)

Key Words; Hibiscus Sabdariffa, Food and Fluid intake, BMI, Onset of Puberty

*Corresponding Author (eghosai@yahoo.com)

Abstracted by:

African Index Medicus (WHO), CAB Abstracts, Index Copernicus, Global Health Abstracts, Asian Science Index, Index Veterinarius, Bioline International , African Journals online 


\section{INTRODUCTION}

The effects of nutrition on the reproductive performance of many species have been recognized for at least a century and this knowledge has been applied to the rearing of domestic species. Since one complete reproductive cycle of ovulation, conception, pregnancy and lactation is one of the most energy consuming activities a female mammal can undertake, particularly in species that bear multiple young (Egelbregt et al, 2001), it therefore follows that with food scarcity, these animals are forced to set priorities, shutting off reproductive functions for the survival of the species (Wade and Schneider, 1992; Wade et al, 1996; Glass et al, 1986).

The 'thrifty phenotype' hypothesis (Hales and Barker, 1992) suggested that when the foetal nutritional environment is poor, there is an adaptive response, which optimizes the growth of key body organs to the detriment of others and leads to an altered postnatal metabolism, which is designed to enhance postnatal survival under conditions of intermittent or poor nutrition. It was proposed that these adaptations only became detrimental when nutrition was more abundant in the postnatal environment, than it had been in the prenatal environment.

A sweetened aqueous extract of Hibiscus sabdariffa (zobo drink) (family: malvaceae) is commonly produced and consumed indiscriminately in Nigeria and extracts of Hibiscus sabdariffa (HS) have been reported to decrease fluid and food intake through a mechanism not yet fully understood (Orisakwe et al, 2003; Orisakwe et al, 2004; Ojokoh, 2006). Thus when aqueous extract of HS is administered to pregnant animals, it may lead to decreased food consumption in these animals with a possible foetal malnutrition and the attendant developmental sequelae (Barker et al, 1993; Gluckman and Hanson, 2004; Armitage et al, 2005a and b).

The present study was therefore designed to investigate the influence of maternal consumption of HS during pregnancy on body weight and the body mass index at onset of puberty in the offspring.

\section{MATERIALS AND METHODS}

\section{Research Design}

The achievement of the aims of the present study was based on the measurement, at onset of puberty (defined as the age in days at which vaginal opening occurred), of the body weight and length and organ weights and weight indices of the female offspring of three groups of SpragueDawley rats given tap water (control), 1.5gextract/Kg body weight/day and 3.0g-extract/Kg body weight/day during pregnancy.

\section{Experimental Animals}

Eighteen in-bred virgin female Sprague-Dawley rats age between 10-12 weeks and weighing $125 \pm$ $5.5 g$ (mean \pm SEM) with two consecutive regular 4-day estrus cycle were used for this study. These rats were housed individually in cages under standard environmental conditions. The estrous cycles were monitored and male rats of proven fertility were introduced into the cages of the female rats that were expected to get into the estrous phase within 12 hours to allow for mating. Day 1 of pregnancy was taken as the day sperm were seen in the vaginal smear of the rats.

On day 1 of pregnancy, animals were divided randomly into three groups of six animals each. The first group (control) was given tap water to drink. The second group was placed on 1.5gextract/Kg body weight/day in their drinking water while the third group received 3.0 g-extract $/ \mathrm{Kg}$ body weight/day in their drinking water. All groups received normal rat chow ad libitum. Fluid and food intake of the dams were measured daily throughout pregnancy. Litter birth weights were also recorded.

On the day of delivery, the HS solutions were withdrawn and replaced with tap water. Each dam in each group was allowed 9 pups to nurse throughout the lactational period so as to eliminate the effect of undernutrition or overnutrition of some of the pups. After 21days, the pups were weaned to tap water. After weaning, the female pups were kept in groups of three per cage. Pups' weights were recorded at birth, weaning and 
weekly thereafter till onset of puberty. Pubertal development starts soon after weaning, so from postnatal day 30 onwards, the young female rats were inspected daily for vaginal opening since onset of puberty is defined as the age (in days) at which vaginal opening occurs (Engelbregt et al, 2000).

At onset of puberty, body weights and lengths of the pups were measured and thereafter, the rats were killed by inhalation of chloroform and the kidney, heart, liver and spleen were excised and weighed for the calculation of the weight indices.

\section{Extraction Procedure}

Mature calyces of HS were purchased from a local market in Enugu, Nigeria, and authenticated at the department of botany, University of Nigeria, Nsukka, Nigeria. The extraction procedure used was as described previously (Iyare and Iyare, 2006a; 2006b). Briefly, 30g of the dry petals of HS was brewed in $400 \mathrm{ml}$ of boiled tap water for 45min. The resulting decoction was filtered and evaporated to dryness giving a dark red powder (yield 48.87\%).

\section{Statistical analysis}

The Student's t-test for paired data was used to analyse data from the same group of rats. For data comparison between the three groups, the one way analysis of variance (ANOVA) was used followed by a post-hoc Student's Newman-Keuls test. $P<0.05$ was taken as statistically significant.

\section{RESULTS}

\section{Maternal Fluid and Food Intake ( $\mathrm{ml} / \mathrm{kg})$}

Dams given HS consumed less $(\mathrm{p}<0.05)$ fluid per day compared with the control dams at all the trimesters of pregnancy. There was a significantly increased fluid intake in the $2^{\text {nd }}$ trimester compared with the fluid intake in the $1^{\text {st }}$ trimester in $1.5 \mathrm{~g} / \mathrm{kg}$ group whereas $3.0 \mathrm{~g} / \mathrm{kg}$ group and group $\mathrm{C}$ showed no difference. $3.0 \mathrm{~g} / \mathrm{kg}$ dams also drank less $(p<0.05)$ fluid in the $2^{\text {nd }}$ trimester compared with $1.5 \mathrm{~g} / \mathrm{kg}$ and Control groups. Fluid intake in the $3^{\text {rd }}$ trimester in groups $1.5 \mathrm{~g} / \mathrm{kg}$ and $3.0 \mathrm{~g} / \mathrm{kg}$ was greater than the fluid intake in the $1^{\text {st }}$ trimester whereas the control group showed no difference. There was a significant difference in fluid intake between the $3^{\text {rd }}$ and the $2^{\text {nd }}$ trimester in $3.0 \mathrm{~g} / \mathrm{kg}$ and Control groups $(3.0 \mathrm{~g} / \mathrm{kg}$ dams higher while Control dams were lower) while fluid intake in group $1.5 \mathrm{~g} / \mathrm{kg}$ dams in the $3^{\text {rd }}$ and $2^{\text {nd }}$ trimester were similar.

Table 1:

Mean fluid intake (ml/kg/day) during pregnancy

\begin{tabular}{|l|l|l|l|}
\hline Group & $\begin{array}{l}1^{\text {st }} \\
\text { trimester }\end{array}$ & $\begin{array}{l}2^{\text {nd }} \\
\text { trimester }\end{array}$ & $\begin{array}{l}3^{\text {rd }} \\
\text { trimester }\end{array}$ \\
\hline Control & 48.75 & 293.93 & 233.72 \\
& \pm 3.61 & \pm 7.29 & \pm 5.3 \\
\hline $1.5 g /$ Kgbwt/day & 146.99 & 182.84 & 187.02 \\
& $\pm 2.07 *$ & $\pm 2.4 *^{\mathrm{P}}$ & $\pm 4.83^{*}$ \\
\hline 3g/Kgbwt/day & 143.2 & 150.77 & $199.97 \pm$ \\
& $\pm 3.15^{*}$ & $\pm 3.58^{*}$ & $9.34^{*}$ \\
\hline
\end{tabular}

$N=6$ each. Values are expressed as Mean \pm SEM

* $\quad \mathrm{p}<0.05$ versus control rats

$\mathrm{P} \quad \mathrm{p}<0.05$ versus $3.0 \mathrm{~g} / \mathrm{kg}$ rats

Table 2:

Mean food consumption (g/kg/day) during pregnancy

\begin{tabular}{|l|l|l|l|}
\hline Group & $\begin{array}{l}1^{\text {st }} \\
\text { trimester }\end{array}$ & $\begin{array}{l}2^{\text {nd }} \\
\text { trimester }\end{array}$ & $\begin{array}{l}3^{\text {rd }} \\
\text { trimester }\end{array}$ \\
\hline Control & 174.0 & 217.02 & 199.36 \\
& \pm 4.59 & \pm 8.94 & \pm 6.12 \\
\hline 1.5g/Kgbwt/day & 140.53 & 176.38 & 168.5 \\
& $\pm 4.68 *$ & $\pm 3.66 *^{\mathrm{P}}$ & $\pm 5.93 *^{\mathrm{P}}$ \\
\hline 3g/Kgbwt/day & 136.01 & 136.76 & 148.25 \\
& $\pm 4.67 *$ & $\pm 3.93 *$ & $\pm 2.48^{*}$ \\
\hline
\end{tabular}

$N=6$ each. Values are expressed as Mean \pm SEM

* $\quad \mathrm{p}<0.05$ versus control rats $\mathrm{p}<0.05$ versus $3.0 \mathrm{~g} / \mathrm{kg}$ rats

\section{Food intake/day/rat}

There was a significant dose-dependent reduction in food intake/day $(\mathrm{p}<0.05)$ in $1.5 \mathrm{~g} / \mathrm{kg}$ and $3.0 \mathrm{~g} / \mathrm{kg}$ groups dams compared with Control group dams at all stages of pregnancy except for the first trimester where there was no significant difference in food intake between $1.5 \mathrm{~g} / \mathrm{kg}$ and $3.0 \mathrm{~g} / \mathrm{kg}$ groups. There was a similar change in food intake in all the groups as pregnancy progressed except in $3.0 \mathrm{~g} / \mathrm{kg}$ group where the food intake by the dams in the $2^{\text {nd }}$ trimester was not different from the $1^{\text {st }}$ trimester but less than $(\mathrm{p}<0.05)$ that of the $3^{\text {rd }}$ trimester. 


\section{Offspring Postnatal Weights}

Results show a significant increase in body weight from birth to postnatal day 28 in groups $1.5 \mathrm{~g} / \mathrm{kg}$ and $3.0 \mathrm{~g} / \mathrm{kg}$ compared with Control group. From postnatal day 35, however, there was a significant increase in body weight in offspring of $3.0 \mathrm{~g} / \mathrm{kg}$ group compared with both group $1.5 \mathrm{~g} / \mathrm{kg}$ and Control offspring. Body weight of group $1.5 \mathrm{~g} / \mathrm{kg}$ offspring was not significantly different from that of Control group offspring.

\section{Body parameters}

There was a significant delay in the age at onset of puberty in groups $1.5 \mathrm{~g} / \mathrm{kg}$ and $3.0 \mathrm{~g} / \mathrm{kg}$ offspring compared with the Control group offspring with group $1.5 \mathrm{~g} / \mathrm{kg}$ rat exhibiting more delay. The body weight and length and BMI at onset of puberty in groups $1.5 \mathrm{~g} / \mathrm{kg}$ and $3.0 \mathrm{~g} / \mathrm{kg}$ offspring were higher than Control group offspring.

Table 3: Mean offspring postnatal weights (g) from birth to postnatal day 42.

\begin{tabular}{|l|l|l|l|l|l|}
\hline Group & PND 0 & PND 21 & PND 28 & PND 35 & PND 42 \\
\hline Control & $5.61 \pm 0.14$ & $22.78 \pm 0.65$ & $32.78 \pm .77$ & $48.33 \pm 0.93$ & $55.83 \pm 1.44$ \\
\hline $1.5 \mathrm{~g} /$ Kgbwt/day & $6.0 \pm .14^{*}$ & $26.94 \pm 1.99^{*}$ & $37.78 \pm 1.21^{*}$ & $44.44 \pm 2.24^{\mathrm{P}}$ & $54.17 \pm 3.06^{\mathrm{P}}$ \\
\hline 3g/Kgbwt/day & $6.11 \pm .12^{*}$ & $28.33 \pm 1.20^{*}$ & $40.56 \pm 1.34^{*}$ & $58.06 \pm 1.29^{*}$ & $76.94 \pm 1.07^{*}$ \\
\hline
\end{tabular}

$N=9$ each. Values are expressed as Mean \pm SEM

* $\quad \mathrm{p}<0.05$ versus control rats

$\mathrm{P} \quad \mathrm{p}<0.05$ versus $3 \mathrm{~g} / \mathrm{Kg} /$ day rats

Table 4:

Some body parameters at onset of puberty.

\begin{tabular}{|l|l|l|l|l|}
\hline \multirow{2}{*}{ Group } & \multicolumn{4}{|c|}{ Parameters at onset of puberty } \\
\cline { 2 - 5 } & Age (g) & Weight (g) & Body length $(\mathbf{c m})$ & BMI (g/cm $)$ \\
\hline Control & $43.11 \pm 1.84$ & $58.89 \pm 1.96$ & $12.9 \pm 0.15$ & $0.35 \pm 0.006$ \\
\hline $1.5 \mathrm{~g} /$ Kgbwt/day & $62.39 \pm 1.84^{\mathrm{P}}$ & $87.22 \pm 2.52^{*}$ & $14.02 \pm .08^{* \mathrm{P}}$ & $0.44 \pm .008^{*}$ \\
\hline $3 \mathrm{~g} /$ Kgbwt/day & $47.56 \pm 0.73^{*}$ & $94.44 \pm 2.94^{*}$ & $14.72 \pm 0.104^{*}$ & $0.44 \pm 0.011^{*}$ \\
\hline
\end{tabular}

$N=9$ each. Values are expressed as Mean \pm SEM

* $\quad \mathrm{p}<0.05$ versus Control

$\mathrm{P} \quad \mathrm{p}<0.05$ versus $3 \mathrm{~g} / \mathrm{Kgbwt} / \mathrm{day}$

Table 5:

Absolute weight of selected visceral organs at onset of puberty.

\begin{tabular}{lllll}
\hline \multirow{2}{*}{ Group } & \multicolumn{4}{l}{ Absolute weight (g) } \\
\cline { 2 - 5 } & Kidney & Heart & Liver & Spleen \\
\hline Control & 0.610 & 0.243 & 2.66 & 0.135 \\
& \pm 0.029 & \pm 0.013 & \pm 0.16 & \pm 0.017 \\
\hline 1.5g/Kgb & 0.890 & 0.432 & 5.082 & 0.520 \\
wt/day & $\pm 0.034^{*}$ & $\pm 0.02 *$ & $\pm 0.122^{*}$ & $\pm 0.041^{*}$ \\
\hline 3g/Kgbwt/ & 0.898 & 0.412 & 5.289 & $0.534 \pm 0$ \\
day & $\pm 0.045^{*}$ & $\pm 0.028^{*}$ & $\pm 0.185^{*}$ & $.040^{*}$ \\
\hline
\end{tabular}

$N=9$ each. Values are expressed as Mean \pm SEM ${ }^{*} \mathrm{p}<0.05$ versus Control
Table 6:

Weight index (x $\left.10^{-3}\right)$ of selected visceral organs at onset of puberty

\begin{tabular}{lllll}
\hline \multirow{2}{*}{ Group } & \multicolumn{4}{c}{ Weight Index } \\
\cline { 2 - 5 } & Kidney & Heart & Liver & Spleen \\
\hline Control & 10.323 & 4.047 & 44.959 & 2.248 \\
& \pm 0.184 & \pm 0.132 & \pm 1.872 & \pm 0.225 \\
\hline 1.5g/Kgb & 10.282 & 4.993 & 58.644 & 5.923 \\
wt/day & \pm 0.539 & $\pm 0.288^{*}$ & $\pm 2.152^{*}$ & $\pm 0.367^{*}$ \\
\hline 3g/Kgbwt/ & 9.552 & 4.378 & 56.175 & 5.674 \\
day & \pm 0.484 & \pm 0.293 & $\pm 1.754^{*}$ & $\pm 0.368^{*}$ \\
\hline
\end{tabular}

$N=9$ each. Values are expressed as Mean \pm SEM $* \mathrm{p}<0.05$ versus Control 


\section{Organ weights and weight index}

The absolute weights and weight index of the heart, liver and spleen were all significantly greater in the groups $1.5 \mathrm{~g} / \mathrm{kg}$ and $3.0 \mathrm{~g} / \mathrm{kg}$ offspring compared with the Control group offspring. The absolute weight of the kidney, but not the weight index, was also greater in the groups $1.5 \mathrm{~g} / \mathrm{kg}$ and $3.0 \mathrm{~g} / \mathrm{kg}$ offspring compared with the Control group offspring.

\section{DISCUSSION}

The decreased food intake in the dams that drank HS may have led to decreased leptin levels in these dams (Maffei et al, 1995; Frederich et al, 1995). Since leptin is transported from the mother to the foetus (Hoggard et al, 1997; Banks et al, 1996), it may have acted as the metabolic signal to the foetus of the status of maternal energy reserves and by extension, environmental food availability thus inducing in the foetus some of the metabolic adaptations that are designed to enhance postnatal survival under conditions of poor nutrition in accordance with the "thrifty phenotype" hypothesis.

The weaning of the pups from dams that were given HS extract during pregnancy to ad libitum food and water may have represented a deviation from the nutritional plane to which the pups had adapted. This metabolic conflict, coupled with the fact that the "thrifty phenotype" offspring are better able to acquire and utilize nutrients and demonstrate an increased risk of obesity as adults (Barker et al, 1993) may have caused the elevated body weight and BMI at onset of puberty.

Since body weight, BMI and plasma leptin levels are highly positively correlated (Butzow et al, 1999; Maffei et al, 1995; Considine et al, 1996; Butte et al, 1997) and since puberty confers reproductive competence, the delayed onset of puberty coupled with high body weight and BMI in the offspring of dams that drank HS during pregnancy may suggest a depression of the leptin signaling pathway that normally informs the brain that energy resources are adequate to support pregnancy. This is inferred from the fact that with food scarcity, animals are forced to set priorities, shutting off reproductive functions for the survival of the species (Wade and Schneider, 1992; Wade et al, 1996; Glass et al, 1986) since one complete reproductive cycle of ovulation, conception, pregnancy and lactation is one of the most energy consuming activities a female mammal can undertake, particularly in species that bear multiple young (Egelbregt et al, 2001).

The cardiomegaly, hepatomegaly and splenomegaly observed in the pups from dams that were given HS extract during pregnancy at onset of puberty may not be unconnected with the metabolic conflict that arose from the weaning of these pups to ad libitum food and water.

We conclude that aqueous extract of HS administered during pregnancy at the doses tested, elevated BMI at onset of puberty in female offspring through mechanism that may depend on disruption of the leptin signaling pathway.

\section{REFERENCES}

Armitage JA, Taylor PD, Poston L (2005a): Experimental models of developmental programming: consequences of exposure to an energy rich diet during development J. Physiol May 15:565 (pt 1): 3-8

Armitage JA, Lakasing L, Taylor PD, Balachandran AA, Jensen RI, Dekou V, Ashton N,Nyengaard JR, Poston L (2005b): Developmental programming of aortic and renal structure in offspring of rats fed fat-rich diets in pregnancy. J. Physiol May 15: 565 (pt 1): 171-184

Banks WA, Kastin AJ, Huang W, Jaspan JB, and Maness LM (1996): Leptin enters the brain by a saturable system independent of insulin.

Peptides.17: 305-311

Barker DJ, Hales CN, Fall CH, Osmond C, Phipps K, Clark PM (1993): Type 2 (non-insulin dependent) diabetes mellitus, hypertension and hyperlipidemia (syndrome $\mathrm{X}$ ): relation to reduced fetal growth.

Diabetologia 36: 62-67. 
Butte NF, Hopkinson JM, Nicolson MA (1997): Leptin in Human Reproduction: Serum Leptin Levels in Pregnant and Lactating Women

The Journal of Clinical Endocrinology \& Metabolism Vol. 82, No. 2 585-589

Butzow, T.L., Moilanen, J.M., Lehtovirta, M. et al. (1999): Serum and follicular fluid leptin during in vitro fertilization: relationship among leptin increase, body fat mass, and reduced ovarian response. J. Clin. Endocrinol. Metab., 84, 31353139.

Considine, RV, Sinha MK, Heiman ML, Kriaucinas A, Stephens TW, Nyce MR, Ohannesian JP, Marco CC, McKee LJ, Bauer TJ, and Caro JF (1996): Serum immunoreactive leptin concentrations in normal weight and obese humans. N. Engl. J. Med.334:292-295

Engelbregt MJT, Houdijk MECAM, PoppSnijders C, Delemarra-van de Waal HA (2000): The effects of intrauterine growth retardation and postnatal undernutrition on onset of puberty in male and female rats. Pediatric Research 48 no6, 803-807

Engelbregt MJT, van Weissenbruch MM, Popp-Snijders C, Lips $P$ and Delemarre-van de Waal HA (2001). Body mass index, body composition and leptin at onset of puberty in male and female rats after intrauterine growth retardation and after early postnatal food restriction. Pediatr Res 50, (4) 474-478.

Frederich RC, Hamann A, Anderson S, Lollman B, Lowell BB., Flier JS (1995): Leptin levels reflect body lipid content in mice: evidence for diet-induced resistance to leptin action. Nat. Med.1:1311-1314.

Glass AR, Herbert DC, Anderson J (1986): Fertility onset, spermatogenesis and pubertal development in male rats: effects of graded underfeeding. Pediatr Res 20: 1161-1167

Gluckman PD, Hanson MA (2004): Developmental origins of disease paradigm: a mechanistic and evolutionary perspective. Pediatr Res; 56, 311-317.

Hales CN and Barker DJ (1992): Type 2 (noninsulin-dependent) diabetes mellitus: the thrifty phenotype hypothesis. Diabetologia 35: 595-601. Hoggard N, Hunter L, Duncan JS, Williams LM, Trayhurn P, Mercer JG (1997): Leptin and leptin receptor mRNA and protein expression in the murine fetus and placenta. Proc Natl Acad Sci USA. 94:11073-11078

Iyare EE, Iyare FE (2006a): Effect of in utero exposure to an aqueous extract of Hibiscus Sabdariffa on offspring's postnatal growth in Sprague-Dawley rats. Nigerian Journal of Health and Biomedical Sciences, vol 5 (1) Jan-June, 2730

Iyare EE, Iyare FE (2006b): Lactational exposure to an aqueous extract of Hibiscus sabdariffa accelerates offspring's early postnatal growth in Sprague-Dawley rats. Journal of Experimental And Clinical Anatomy 5(1): 6-9

Maffei MJ, Halaas J, Rayussin E, Pratley RE, Lee GM, Zhang Y, Fei H, Kim S, Lallone R, Ranganathan S, et al(1995): Leptin levels in human and rodent: measurement of plasma leptin and ob mRNA in obese and weightreduced subjects. Nat. Med.1:1155-1161.

Ojokoh AO (2006): Roselle (Hibiscus Sabdariffa) calyx diet and histopathological changes in liver of Albino rats. Pakistan Journal of nutrition 5(2) 110113.

Orisakwe OE, Hussaini DC, Akunyili DN, Njan AA, Akumka DD, Udemezue $O O$ (2004): Subchronic administration of Nigerian species of Hibiscus Sabdarffa calyx in rats did not produce cardiotoxicity. European Bulletin of Drug Research volume 12, Pp 1-5.

Orisakwe OE, Hussaini DC, Orish VN, Obi E, Udemezue OO (2003): Nephrotoxic effects of Hibiscus Sabdariffa calyx in Rats. European Bulletin of Drug Research volume 11, No 4 Pp 99-103.

Wade GN and SchneiderJE (1992): Metabolic fuels and reproduction in female mammals. Neurosci Biobehav Rev 16:235-272.

Wade GN, Schneider JE, Li HY (1996): Control of fertility by metabolic cues. Am J of Physiol 270: E1-E19. 